\title{
Motivating and Discouraging Factors for Bipolar Patient Participation in Genomic Research
}

\author{
Eric J. Vallender ${ }^{a}$ Mark E. Ladner ${ }^{a}$ Margaret O. Akinhanmi ${ }^{b}$ Felicia V. Caples $^{c}$ \\ Mark A. Frye ${ }^{d}$ Joyce E. Balls-Berry ${ }^{d, e}$ \\ ${ }^{a}$ Department of Psychiatry and Human Behavior, University of Mississippi Medical Center, Jackson, MS, USA; \\ bSatcher Health Leadership Institute, Morehouse School of Medicine, Atlanta, GA, USA; 'Department of Behavioral \\ and Environmental Health, Jackson State University, Jackson, MS, USA; dDepartment of Psychiatry and Psychology,

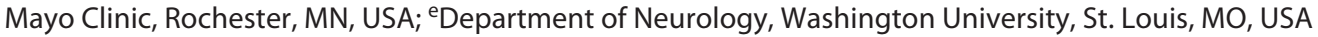

\section{Keywords}

Biobank · Ethnic/racial minorities · Psychiatric genetics · Community-based participatory research

\begin{abstract}
Aims: The goal of this project was to better understand the motivating and discouraging factors toward genetic research and biobank programs in patients with bipolar disorder, particularly across gender and racial identities. Methods: A survey $(n=63)$ of adults diagnosed with bipolar disorder was conducted at the general psychiatric inpatient unit and outpatient clinic at the University of Mississippi Medical Center. Participants were asked to rate on a Likert scale their attitudes toward medical research generally, mental health research specifically, and willingness to participate in a bipolar DNA biobank. Last, they were asked to endorse motivating factors or concerns for their attitude toward participation. Results: Neither attitudes toward research nor willingness to participate in a bipolar biobank differed across gender, age, or education level, but Black/African American participants were statistically significantly less likely to endorse a willingness to participate in a biobank
\end{abstract}

karger@karger.com www.karger.com/phg

Karger $\stackrel{\text { ' }}{5}$

GOPEN ACCESS
(C) 2021 The Author(s)

Published by S. Karger AG, Basel

This is an Open Access article licensed under the Creative Commons Attribution-NonCommercial-4.0 International License (CC BY-NC) (http://www.karger.com/Services/OpenAccessLicense), applicable to the online version of the article only. Usage and distribution for commercial purposes requires written permission. compared to White participants. As observed in previous work, Black/African American participants were significantly more likely to endorse concerns regarding violations of trust, privacy, or autonomy. However, while there were no significant differences in discouraging factors among individuals who indicated an opposition to participating in a biobank compared to those who indicated support, there was a significant decrease in support of motivating factors, including increasing knowledge, personal benefit, and duty to community, for those not interested in participating. Conclusions: Black/African American participants with bipolar disorder were more likely to express concerns about DNA and biobank research. But while race was a contributing factor to support or opposition to biobanking for bipolar disorder research, more salient was insufficient positive motivation. These results highlight the need to emphasize contemporary safeguards on DNA research and biobanking as an ethical duty and to identify the need for community-based educational interventions to promote a greater understanding of the positive benefits to motivate increased research participation.

(c) 2021 The Author(s)

Published by S. Karger AG, Basel
Eric J. Vallender

Department of Psychiatry and Human Behavior

University of Mississippi Medical Center

2500 N. State St., Jackson, MS 39216 (USA)

evallender@umc.edu 


\section{Introduction}

Family and twin studies have unequivocally established a genetic basis for bipolar disorder [1-4]. While family and twin-based studies consistently find heritability levels of $60-85 \%$ [5], recent work based on single-nucleotide polymorphism (SNP)-based heritability levels reflect estimates of approximately $20-25 \%[6,7]$. This consistently places bipolar disorder among the most genetically influenced of psychiatric [6-9] and other complex diseases [10-12]. Existing genome-wide association studies (GWAS) of bipolar disorder have already identified 30 loci associated with the disease $[13,14]$, though this is expected to continue to rise substantially [15]. Identification of genetic risk factors associated with bipolar disorder potentially adds value to early diagnostic/ clinical staging paradigms and may provide greater precision to interventional strategies. These are important because the onset of diagnosis and treatment for bipolar disorder is often delayed by more than a decade, regularly as a result of misdiagnosis. As reviewed by Akinhanmi et al. [16], this misdiagnosis and its clinical implications have greater prominence in bipolar persons of African ancestry $[17,18]$.

Biobanks are an increasingly important modern biomedical tool for consolidating the collection of human biological samples linked with sociodemographic and clinical information. This allows them to easily facilitate research into genetic risk of disease utilizing richly described clinical data or phenotypic information. Largescale GWAS, particularly for complex disease, require extremely large sample sizes to attain statistical significance. The collection of these DNA samples with high quality phenotypic information is increasingly the bottleneck in these endeavors. Biobanks centralize the collection of these data, increasing accessibility and proactively accumulating the samples and data. Biobanks from countries with nationalized health care (e.g., Iceland [19], United Kingdom [20]) have allowed for GWAS across numerous modalities with great success. Similar programs in the United States are recently underway (e.g., All of Us Research Program [21], Million Veteran Program [22]).

For a variety of reasons, existing biobanks and GWAS are dominated by populations with specific demographics, White individuals, or Europeans. This disparity has been noted generally [23-25], in research on mental health $[26,27]$, and in bipolar disorder [16]. In general surveys of GWAS research, more than $80 \%$ of individuals with available information are of European ancestry and $10 \%$ of Asian (mostly East Asian) ancestry; fewer than
$3.5 \%$ of individuals have non-European/non-Asian ancestry and 2\% African ancestry [25]. For bipolar disorder, the most recent GWAS used 29,000 individuals of European ancestry [14], but the largest study to date using Black/African Americans individuals remains a study with a sample size of 345 from 2009 [28]. Results from GWAS may or may not generalize across populations. The dearth of these subpopulations in genetic studies is a problem that likely perpetuates health disparities in medical health and impedes universal medical advances for all patients.

Participation in biobanks and genetic research, particularly in countries with privatized health care such as the United States, has depended upon the willingness of participants to make genetic data and phenotypic measures available to researchers. Attitudes and perceptions regarding participation vary based on social and cultural mores. For example, survey results from the Depression Bipolar Support Alliance, the largest grass roots advocacy group for bipolar disorder, identified that funding source and management of the biobank (i.e., clinic/university, government, and industry) was an important factor in considering study participation, as well as professional and mental health consumer opinion and return of research results [29]. Potential participants often express the need for additional information when coming to a decision regarding participation. This includes broad understandings of genetic research, how biobanks operate, and cost/benefit analyses [30]. One of the most common misunderstandings for participants surrounds therapeutic relevance, the false belief that participation in a biobank will lead to personalized results or clinical care [31]. The success or failure of biobanks and their ethical governance are dependent upon taking these factors into consideration and reflecting participant concerns.

While these issues are broadly relevant, they take on added importance for groups of peoples that have been historically disenfranchised and exploited, most notably Black/African American populations. A full and dutiful exploration of the historical and ongoing issues of discrimination and unethical behavior, specifically of the biomedical community, toward Black/African American populations in the United States that have led to this point is beyond the scope of the present work and more ably discussed elsewhere [32-35], but it is sufficient here to recognize that qualitative research has previously demonstrated that Black/African American populations may demonstrate unique patterns of concerns compared to other racial groups both regarding medical research generally [36] and in biobanks in particular [37]. The present
Public Health Genomics 2021;24:89-98 DOI: $10.1159 / 000513723$
Vallender/Ladner/Akinhanmi/Caples/ Frye/Balls-Berry 
Table 1. Demographic comparison among groups

\begin{tabular}{llllll}
\hline $\begin{array}{l}\text { Demographics in 2018 } \\
\text { (adults 18-85) }\end{array}$ & $\begin{array}{l}\text { State, } \\
\%\end{array}$ & $\begin{array}{l}\text { Medical } \\
\text { center, } \\
\%\end{array}$ & $\begin{array}{l}\text { Psychiatry } \\
\text { department } \\
\text { (all), \% }\end{array}$ & $\begin{array}{l}\text { Psychiatry } \\
\text { department } \\
\text { (bipolar), \% }\end{array}$ & $\begin{array}{l}\text { Survey } \\
\text { participants, } \\
\%\end{array}$ \\
\hline White & 60.7 & 41.4 & 43.3 & 60.1 & 62.3 \\
$\quad$ Male & 30.0 & 17.2 & 19.1 & 22.4 & 16.4 \\
$\quad$ Female & 30.8 & 24.2 & 24.2 & 37.7 & 45.9 \\
Black/African American & 36.7 & 49.1 & 50.9 & 35.8 & 24.6 \\
$\quad$ Male & 16.8 & 17.3 & 18.7 & 15.1 & 13.1 \\
$\quad$ Female & 19.8 & 31.8 & 32.2 & 20.7 & 11.5 \\
Other ancestry & 2.6 & 9.5 & 5.8 & 4.1 & 13.1 \\
$\quad$ Male & 1.2 & 3.7 & 2.5 & 1.5 & 4.9 \\
$\quad$ Female & 1.3 & 5.9 & 3.3 & 2.6 & 8.2 \\
\hline Total number & 2.23 mil & 221,202 & 10,219 & 615 & 63 \\
\hline
\end{tabular}

study was undertaken to better understand attitudes, interests, and driving factors that impact consideration of research participation in bipolar patients in a predominantly Black/African American community.

\section{Methods}

Based on previous literature, a community and patient engaged research studio was used to develop a cross-sectional mixed-methods questionnaire [38]. This work was done in concert with the University of Mississippi Medical Center (UMMC) Bipolar Biobank Community Advisory Board (CAB). The CAB consists of 15 members (12 female and 3 male; 4 White and 11 Black/African American) representative of the Jackson, Mississippi community with an emphasis on patients, patient advocates, resource providers, and clinical providers.

This study was approved by the UMMC Institutional Review Board (\#2018-0184). The survey was distributed to patients with bipolar disease recruited from UMMC inpatient psychiatric units after completion of treatment and outpatient clinics during routine follow-up visits. To be eligible, patients were required to be between the age of 18 and 85 inclusive, able to read and speak English, provide informed consent, and have been previously diagnosed with bipolar disorder by a UMMC provider.

All surveys were anonymous. Participants were provided with a letter detailing the study and contact information to obtain more information, the survey itself, and an envelope. All eligible survey participants were provided with the material and could choose to return a completed or partially completed survey, a blank survey, or not to return anything. Sealed envelopes were placed in a locked box and collected once per month. The survey was separate from clinical care and providers were unaware if or when a patient participated.

The questionnaire was adapted from earlier work [38] and included demographic questions on gender, age, race, ethnicity, education, and previous experience with biomedical research. Participants were asked "How much do you support or oppose re- search involving human subjects for the purpose of learning more about health disorders in general?" and separately "mental health disorders such as bipolar disorder, depression, and schizophrenia?" Response choices were on a Likert scale of "strongly support," "support," "oppose," and "strongly oppose." A description of a biobank, "a collection of blood samples from people in our community for research on bipolar disorder... to learn more about people with bipolar disorder by studying the DNA (genetic information) found in their blood samples," was provided and participants were asked, "In the future, would you be willing to consider giving a sample of blood for your DNA to be used in this type of project?"

Participants were then asked to select factors that influenced their decision including 5 putatively positive motivating factors: "To increase knowledge of bipolar disorder," "Personal benefit," "Benefit to a family member," "Sense of duty to the community," "Because my doctor asks me to participate"; 5 putatively demotivating factors: "Worry about research that uses DNA," "Worry about a violation of trust," "Worry that DNA may be used against me," "Worry that DNA may be used for something other than research," "Afraid of needles/injections"; the general "No specific reason"; and an open-ended "Other" which they were able to elaborate upon.

Demographics of participants were compared to those of all patients with bipolar disorder seen in the clinics that formed the basis for recruitment to address concerns of participation bias. Among the participant data, attitudes toward research and willingness to consider participation in a biobank were compared to demographic variables. Motivating and demotivating factors were compared to demographic variables as well as willingness to consider participation in a biobank.

There was an interest in trying to understand the relative racial diversity of the survey participants and the surveyed population compared to the broader university hospital community and the state of Mississippi. Demographic information on the state as a whole and the catchment area for UMMC was obtained from the Census Bureau [39]. Unique patients seen at UMMC for any reason, unique patients seen by UMMC Department of Psychiatry regardless of diagnosis, and unique patients seen by the UMMC 

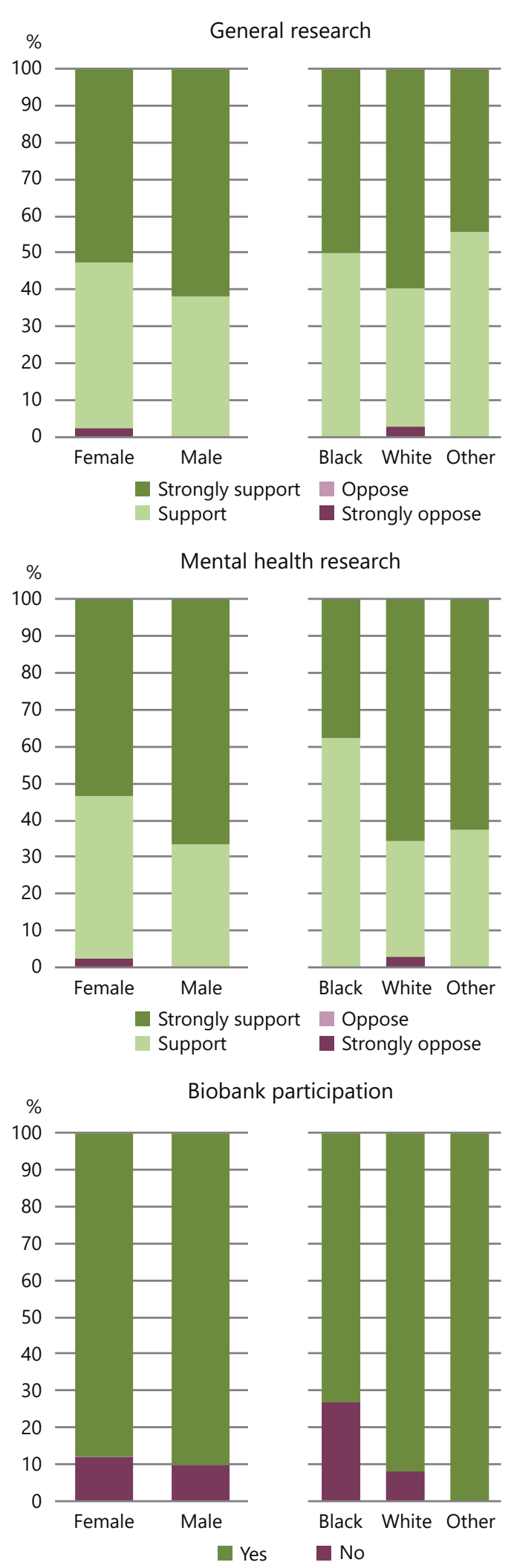

Department of Psychiatry with a bipolar diagnosis were compiled using the Patient Cohort Explorer, a local tool developed for accessing de-identified data compiled from EHR [40].

A two-tailed $\chi^{2}$ test, or Fisher's Exact test when cell size was $<40$, was used to identify independence of variables in contingency tables. The nonparametric Mann-Whitney U test or Kruskal-Wallis test, as appropriate, was used to compare discrete variables. A logistic regression model (binomial) was then used for subsequent examination of the groups. All statistical tests were carried out in $\mathrm{R}$ (v.3.6.3) [41] using the "arsenal" package version 3.5.0 [42]. After completion of data analysis, the $\mathrm{CAB}$ reviewed the results and participated in the interpretation of study findings.

\section{Results}

Surveys were distributed from 4 recruitment locations between 1 January 2019, and 31 October 2019, to individuals with a bipolar diagnosis. A total of 613 individuals that met criteria were seen at these locations during the study period, and $63(10.2 \%)$ returned completed surveys. Demographic information was from the state, unique patients seen at UMMC, and unique patients seen by the UMMC Department of Psychiatry, in general and with a bipolar diagnosis, and survey participants is presented in Table 1. White bipolar patients represented the majority (62.3\%) of survey participants, followed by Black/African American (24.6\%). Across all categories, females were significantly overrepresented relative to males. The percentage of Black/African American bipolar patients (35.8\%) was significantly different from both the UMMC general patient population $\left(49.1 \%, \chi^{2}=1,046.1,2 \mathrm{df}, p<\right.$ 0.0001 ) and the Department of Psychiatry general patient population $\left(50.9 \%, \chi^{2}=66.85,2 \mathrm{df}, p<0.0001\right)$.

While there were no significant differences between survey participants and UMMC Department of Psychiatry bipolar patients more broadly in age $\left(\chi^{2}=2.59,4 \mathrm{df}\right.$, $p=0.629)$ or gender $\left(\chi^{2}=0.43,1 \mathrm{df}, p=0.512\right)$, there was a statistically significant difference observed in race with a higher rate of participants whose self-reported race was something other than "White" or "Black/African American" driven largely by individuals who endorsed multiple racial backgrounds $\left(\chi^{2}=11.27,2 \mathrm{df}, p=0.004\right)$. When only comparing White and Black/African American

Fig. 1. Attitudes toward research using humans for better understanding of health disorders generally or mental health disorders specifically with support measured using a forced choice Likert scale and likelihood of bipolar biobank participation with breakdowns by race and gender. 


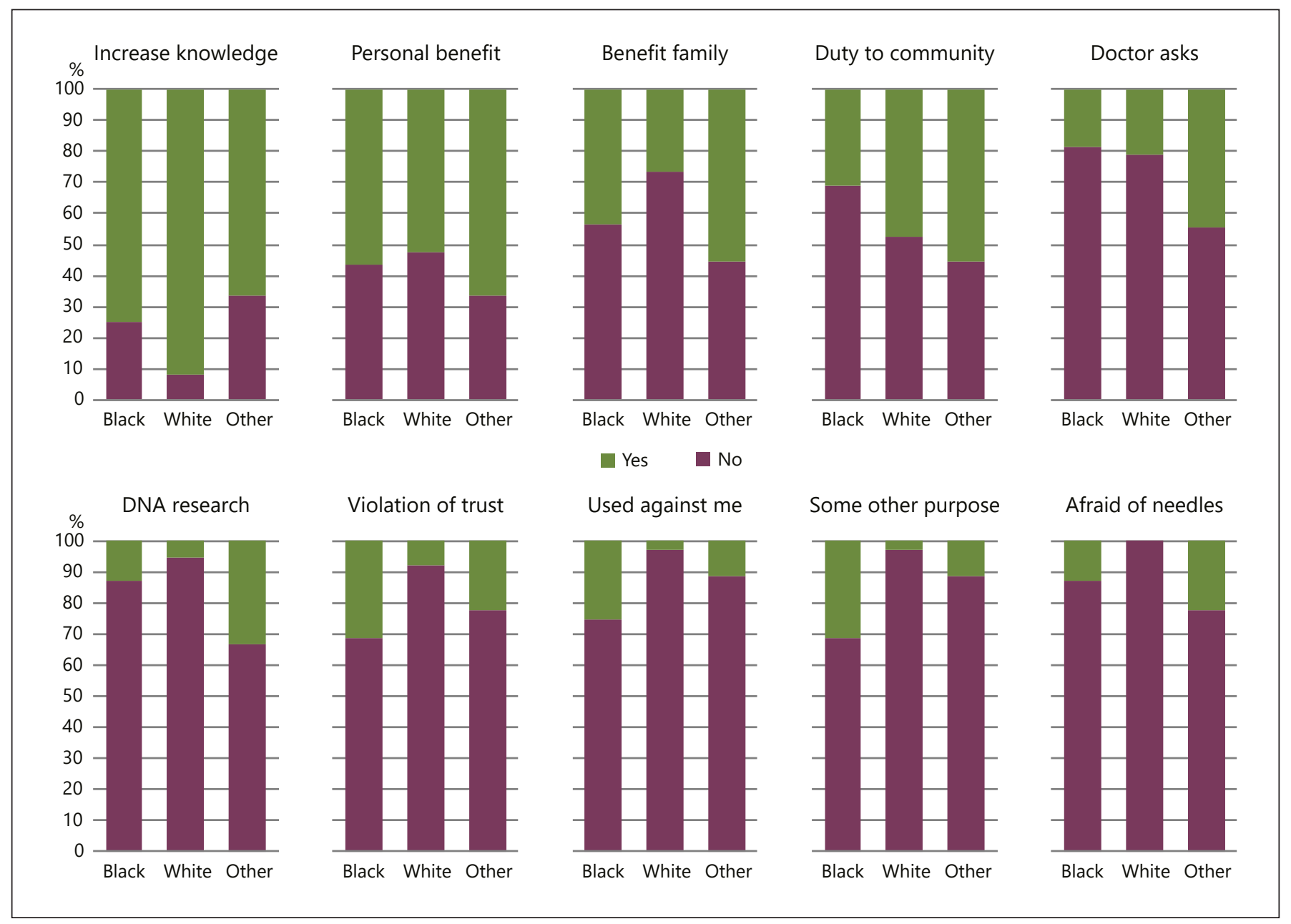

Fig. 2. Endorsement - agree or disagree - of various motivating or discouraging factors for participation in a bipolar biobank by race.

individuals, there was no difference $\left(\chi^{2}=1.54,1 \mathrm{df}, p=\right.$ 0.215).

As presented in Figure 1, there was no significant difference in survey participants' attitudes toward research involving humans on health disorders based on gender $(U=$ $380.5, p=0.519)$, race $(U=272, p=0.710)$, age $(H(4)=$ 5.593, $p=0.232)$, or education $(H(5)=5.916, p=0.315)$. There was a significant effect of age $(H(4)=11.09, p=$ $0.026)$ and trend for race $(U=223, p=0.074)$ in attitudes toward research involving humans for mental health disorders, but not gender $(U=374.5, p=0.363)$ or education $(H(5)=1.685, p=0.891)$. Black/African American survey participants were significantly less likely to endorse a willingness to participate in a genetic biobank than White survey participants $(U=229.5, p=0.047)$; there were no other significant differences by gender $(U=402, p>0.999)$, age $(H(4)=2.986, p=0.560)$ and education $(H(5)=2.357$, $p=0.798)$. There were no significant differences between genders within racial categories on any question.

As presented in Figure 2, survey participants did not have significant differences in positive motivating factors for participation in genomic research. However, Black/ African American individuals were more likely to endorse discouraging factors including violations of trust $(p=0.041)$, privacy $(p=0.023)$, and autonomy $(p=0.007)$. Logistic regression modeling identified "violation of trust" and "being used against me" as significant factors associated with race (Table 2). As presented in Figure 3, survey participants who indicated an opposition to participating in a biobank, compared to those who indicated support, were significantly less likely to endorse support of motivating factors including increasing knowledge 


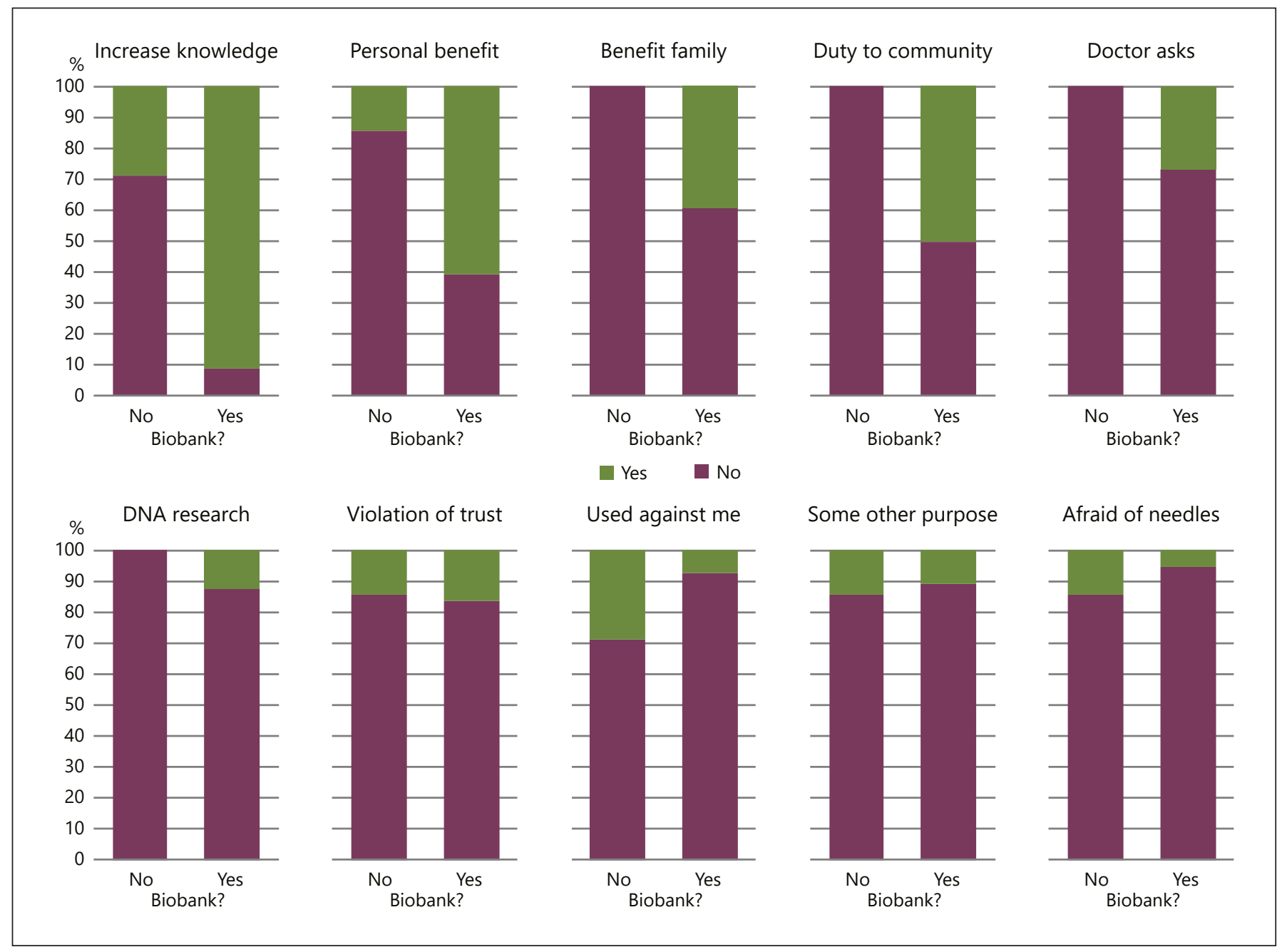

Fig. 3. Endorsement - agree or disagree - of various motivating or discouraging factors for participation in a bipolar biobank by response to survey question on consideration of participation in a bipolar biobank.

Table 2. Logistic regression modeling of likelihood to endorse motivating or discouraging factors by race and gender

\begin{tabular}{|c|c|c|c|c|c|c|}
\hline & \multicolumn{3}{|c|}{ Gender } & \multicolumn{3}{|l|}{ Race } \\
\hline & OR & $\mathrm{CI}$ & $p$ value & OR & CI & $p$ value \\
\hline Increase knowledge & 0.750 & $0.100-3.926$ & 0.747 & 0.257 & $0.045-1.323$ & 0.103 \\
\hline Personal benefit & 0.847 & $0.265-2.654$ & 0.776 & 1.157 & $0.357-3.851$ & 0.808 \\
\hline Benefit family & 1.357 & $0.402-5.043$ & 0.631 & 2.178 & $0.632-7.508$ & 0.212 \\
\hline Duty to community & 0.937 & $0.297-3.002$ & 0.912 & 0.505 & $0.137-1.678$ & 0.278 \\
\hline Doctor asks & 0.538 & $0.137-2.164$ & 0.370 & 0.865 & $0.169-3.556$ & 0.848 \\
\hline DNA research & 0.485 & $0.054-4.339$ & 0.489 & 2.571 & $0.286-23.19$ & 0.368 \\
\hline Violation of trust & 0.833 & $0.179-4.500$ & 0.819 & 5.303 & $1.124-29.44$ & 0.039 \\
\hline Used against me & 0.750 & $0.113-6.127$ & 0.765 & 12.33 & $1.633-254.2$ & 0.031 \\
\hline Used for something else & 0.485 & $0.054-4.339$ & 0.489 & 8.538 & $0.996-181.3$ & 0.074 \\
\hline Afraid of needles & Inf & 0 -Inf & 0.999 & Inf & 0 -Inf & 0.999 \\
\hline
\end{tabular}

$p$ values $<0.05$ are shown in bold and italics. 
Table 3. Logistic regression modeling of response to consideration of participation in a bipolar biobank

\begin{tabular}{lllr}
\hline & OR & CI & $p$ value \\
\hline Gender & 1.000 & $0.128-5.750$ & 1.000 \\
Race & $\mathbf{0 . 1 5 7}$ & $\mathbf{0 . 0 2 0 - 0 . 9 1 5}$ & $\mathbf{0 . 0 4 7}$ \\
Increase knowledge & $\mathbf{4 4 . 0 0}$ & $\mathbf{5 . 5 9 8}-\mathbf{5 4 0 . 2}$ & $<\mathbf{0 . 0 0 1}$ \\
Personal benefit & 7.105 & $1.037-142.0$ & 0.084 \\
Benefit family & Inf & 0-Inf & 0.999 \\
Duty to community & Inf & 0-Inf & 0.999 \\
Doctor asks & Inf & 0 -Inf & 0.999 \\
DNA research & Inf & 0 -Inf & 0.999 \\
Violation of trust & 0.897 & $0.118-18.55$ & 0.926 \\
Used against me & 0.140 & $0.017-1.285$ & 0.061 \\
Used for something else & 0.349 & $0.036-7.787$ & 0.399 \\
Afraid of needles & 0.111 & $0.004-3.094$ & 0.140 \\
\hline
\end{tabular}

$p$ values $<0.05$ are shown in bold and italics.

( $p=0.001)$, personal benefit $(p=0.038)$, and duty to community ( $p=0.014)$. There were no significant differences in discouraging factors. Logistic regression modeling identified race and "increasing knowledge" as significant factors in considering participation in a bipolar biobank (Table 3). So, while Black/African American participants generally were more likely to endorse discouraging factors surrounding genetic research (Fig. 2; Table 2), these factors were not those that were significantly associated with the decrease in biobank participation. Those individuals who would not consider biobank participation were motivated not by the presence of negative factors but rather by the absence of any positive factors (Fig. 3; Table 3).

\section{Discussion}

The findings on racial differences in participants with bipolar disorder, both increased discouraging and decreased motivating factors, align with previous studies in other populations of patients with other diseases and/or from other geographic areas. Black/African American individuals report higher levels of concerns regarding violations of trust, privacy, and autonomy in their dealings with the medical community [43]. This apprehension extends to participation in genetic biobanking of psychiatric disorders where in recent studies, Black/African American adults expressed concerns about exploitation, distrust of researchers, investigators' motives, and personal and biological data access and privacy [37]. Further, previous work from the US Bipolar Genome Study (BiGS)

Community Concerns for Bipolar

Biobanking reported that while White and Black/African American participants were both concerned about research participation and the associated possible negative consequences related to medical insurance (63\%), job security (59\%), and stigma (57\%), concerns about racial discrimination (Black $/$ African American $=50 \%$, White $=25 \%)$ were significantly different between the racial groups [44]. During discussions with the UMMC Bipolar Biobank CAB these concerns were reiterated. Nonetheless, members voiced that this research was necessary and that further educational opportunities around genetic research and bipolar disorder was warranted. While we observe these same issues in our population, it is notable that they do not seem to translate into a decreased willingness to participate in a bipolar biobank. We instead find that while these concerns are present, the participants that expressed them had similar attitudes toward medical and mental health research and still were willing to participate in a biobanking project. These findings are in concordance with previous research on Black/African American decision-making in the context of genomics research outside of the mental health context [45].

Conversely, the individuals that ultimately did not express a willingness to participate in a biobanking effort did not show any increased concerns but rather did not see any positive motivating factors to participation. While individuals willing to participate endorsed a number of activating factors, these were almost entirely absent among participants who indicated they were not interested. This suggests that in recruitment for a biobank, the major effort may not be in allaying concerns, though this certainly still exists as an ethical imperative, but rather in emphasizing the positive aspects of participation.

It is important, however, to note that among individuals willing to participate in a biobank, there were elevated levels of perception of benefits that do not exist. More than $50 \%$ of individuals said that "personal benefit" motivated their participation and roughly $25 \%$ said they would participate "because my doctor asks." This highlights a need for education, even among those predisposed to participation, both from the standpoint of benefits of research participation (i.e., knowledge of illness and possible benefit to younger family members and society) and therapeutic misconception [46]. Those asked to participate in a biobanking project need to have a clear understanding of what it can and cannot do and what they can expect to get from participation.

The racial and gender composition of our survey participants were not statistically different from the larger 
population of bipolar patients seen in our clinics. We did observe a greater percentage of participants indicating racial identities other than exclusively "White" or "Black/ African American" in our survey compared to those indicated in the electronic health records, but this seems likely to reflect a difference in categorization (and perhaps a deficit of the electronic health records) rather than a meaningful response difference. Males were slightly less likely to participate in the survey compared to females, in line with previous studies, but this was not significant.

One possible confound to our study comes from participation bias. While lower than hoped, the observed rate of survey return was not out of line with a priori expectations [47], especially accounting for historical distrust and the complexity associated with a bipolar disorder diagnosis. Moreover, this response rate is likely to be a conservative estimation since no tracking of survey recipients occurred to maintain anonymity in participation as well as response; thus, the denominator in response rate, total patients seen in the clinics with bipolar disorder during the survey period, may overestimate the number of patients who received the survey. While survey response rates were lower than hoped, however, the response rates of specific demographic groups did not vary significantly.

In our $\mathrm{CAB}$ meetings, when discussing this project with patient stakeholders, one concern that was raised was that individuals most likely to worry about violations of trust of privacy were also those most likely to choose not to participate in the survey despite its anonymity. This participation bias may lead to an overestimate of support for medical and biomedical research, participation in a biobank, endorsement of positive motivating factors, or underestimates of negative motivating factors. Again, however, given that we appear to have comparable demographics among our survey completers and our general bipolar population, it would appear that this participation bias would not affect the larger demographic findings. While this work would certainly benefit from an increased sample size, the existing findings and concerns about participation bias have lead us to focus on other aspects of community-based participatory research [48].

This survey should be seen as a guidepost on how best to develop biobanks, particularly in our efforts to increase diversity and equity in genetic studies. To more effectively promote the value of biobanking and genetic research to participants, we need to not only emphasize the ethical safeguards in place but also to demonstrate what the re- search hopes to achieve and how these efforts will directly impact these goals. These data represent targets for community-based educational interventions to promote a greater understanding of the positive benefits to society to motivate increased research participation. While our study has focused on bipolar disorder, it will be of interest to see if these patterns hold across other psychiatric diseases or in diseases that do not harbor the same social stigma as mental health.

\section{Acknowledgements}

The authors would like to thank all those who participated in the survey and the UMMC Bipolar Biobank Community Advisory Board members for their invaluable insight and support throughout the process.

\section{Statement of Ethics}

This study was approved by the University of Mississippi Medical Center Institutional Review Board (\#2018-0184).

\section{Conflict of Interest Statement}

Dr. Frye has received grant support from Assurex Health and Medibio. He has served as a consultant to Actify Neurotherapies, Allergan, Intra-Cellular Therapies, Janssen, Myriad, Neuralstem, Takeda, and Teva Pharmaceuticals. He has continuing medical education support from the American Physician Institute, CME Outfitters, and Global Academy for Medical Education. The other authors have no conflicts of interest to declare.

\section{Funding Sources}

This work was supported through internal funding support from the University of Mississippi Medical Center and the Mayo Foundation.

\section{Author Contributions}

All authors participated in the design and analysis of the study. Dr. Vallender and Dr. Ladner collected survey data at UMMC. Dr. Caples, Dr. Akinhanmi, and Dr. Balls-Berry oversaw and supported the Community Advisory Board. All authors were active in the preparation of the data for publication and approved the final version of the manuscript.
Vallender/Ladner/Akinhanmi/Caples/ Frye/Balls-Berry 


\section{References}

1 Kendler KS, Pedersen N, Johnson L, Neale MC, Mathé AA. A pilot Swedish twin study of affective illness, including hospital- and population-ascertained subsamples. Arch Gen Psychiatry. 1993 Sep;50(9):699-700.

2 Birmaher B, Axelson D, Monk K, Kalas C, Goldstein B, Hickey MB, et al. Lifetime psychiatric disorders in school-aged offspring of parents with bipolar disorder: the Pittsburgh bipolar offspring study. Arch Gen Psychiatry. 2009 Mar;66(3):287-96.

3 Rasic D, Hajek T, Alda M, Uher R. Risk of mental illness in offspring of parents with schizophrenia, bipolar disorder, and major depressive disorder: a meta-analysis of family high-risk studies. Schizophr Bull. 2014 Jan;40(1):28-38.

4 Mesman E, Birmaher BB, Goldstein BI, Goldstein T, Derks EM, Vleeschouwer M, et al. Categorical and dimensional psychopathology in Dutch and US offspring of parents with bipolar disorder: a preliminary crossnational comparison. J Affect Disord. 2016 Nov 15;205:95-102.

5 Fabbri C. The role of genetics in bipolar disorder. Curr Top Behav Neurosci. 2020 Aug 7.

6 Cross-Disorder Group of the Psychiatric Genomics Consortium, Lee SH, Lee SH, Ripke S, Neale BM, Faraone SV, et al. Genetic relationship between five psychiatric disorders estimated from genome-wide SNPs. Nat Genet. 2013 Sep;45(9):984-94.

7 Cross-Disorder Group of the Psychiatric Genomics Consortium. Genomic relationships, novel loci, and pleiotropic mechanisms across eight psychiatric disorders. Cell. 2019 Dec 12;179(7):1469-e11.

8 Pettersson E, Lichtenstein $\mathrm{P}$, Larsson $\mathrm{H}$, Song J, Agrawal A, Agrawal A, et al. Genetic influences on eight psychiatric disorders based on family data of 4,408,646 full and half-siblings, and genetic data of 333,748 cases and controls. Psychol Med. 2019 May; 49(7):1166-73.

9 Sullivan PF, Geschwind DH. Defining the genetic, genomic, cellular, and diagnostic architectures of psychiatric disorders. Cell. 2019 Mar 21;177(1):162-83.

10 Speed D, Cai N, Johnson MR, Johnson MR, Nejentsev S, Balding DJ. Reevaluation of SNP heritability in complex human traits. Nat Genet. 2017 Jul;49(7):986-92.

11 Hou K, Burch KS, Majumdar A, Shi H, Mancuso $\mathrm{N}, \mathrm{Wu} \mathrm{Y}$, et al. Accurate estimation of SNP-heritability from biobank-scale data irrespective of genetic architecture. Nat Genet. 2019 Aug;51(8):1244-51.

12 Speed D, Balding DJ. SumHer better estimates the SNP heritability of complex traits from summary statistics. Nat Genet. 2019 Feb;51(2):277-84.
13 Psychiatric GWAS Consortium Bipolar Disorder Working Group, Sklar P, Ripke S, Scott LJ, Andreassen OA, Cichon S, et al. Largescale genome-wide association analysis of bipolar disorder identifies a new susceptibility locus near ODZ4. Nat Genet. 2011 Sep 18; 43(10):977-83.

14 Stahl EA, Breen G, Forstner AJ, McQuillin A, Ripke S, Trubetskoy V, et al. Genome-wide association study identifies 30 loci associated with bipolar disorder. Nat Genet. 2019 May; 51(5):793-803.

15 Gratten J, Wray NR, Keller MC, Visscher PM. Large-scale genomics unveils the genetic architecture of psychiatric disorders. Nat Neurosci. 2014 Jun;17(6):782-90.

16 Akinhanmi MO, Biernacka JM, Strakowski SM, McElroy SL, Balls Berry JE, Merikangas $\mathrm{KR}$, et al. Racial disparities in bipolar disorder treatment and research: a call to action. Bipolar Disord. 2018 Sep;20(6):506-14.

17 Lish JD, Dime-Meenan S, Whybrow PC, Price RA, Hirschfeld RM. The National Depressive and Manic-depressive Association (DMDA) survey of bipolar members. J Affect Disord. 1994 Aug;31(4):281-94.

18 Hirschfeld RM, Lewis L, Vornik LA. Perceptions and impact of bipolar disorder: how far have we really come? Results of the national depressive and manic-depressive association 2000 survey of individuals with bipolar disorder. J Clin Psychiatry. 2003 Feb;64(2):16174.

19 Arnar DO, Palsson R. Genetics of common complex diseases: a view from Iceland. Eur J Intern Med. 2017 Jun;41:3-9.

20 Sudlow C, Gallacher J, Allen N, Beral V, Burton P, Danesh J, et al. UK biobank: an open access resource for identifying the causes of a wide range of complex diseases of middle and old age. PLoS Med. 2015 Mar;12(3): e1001779.

21 Denny JC, Denny JC, Rutter JL, Goldstein DB, Philippakis A, Smoller JW, et al. The "all of us" research program. N Engl J Med. 2019 Aug 15;381(7):668-76

22 Gaziano JM, Concato J, Brophy M, Fiore L, Pyarajan S, Breeling J, et al. Million veteran program: a mega-biobank to study genetic influences on health and disease. J Clin Epidemiol. 2016 Feb;70:214-23.

23 Peprah E, Xu H, Tekola-Ayele F, Royal CD. Genome-wide association studies in Africans and African Americans: expanding the framework of the genomics of human traits and disease. Public Health Genomics. 2015; 18(1):40-51

24 Mills MC, Rahal C. A scientometric review of genome-wide association studies. Commun Biol. 2019 Jan;2:9.

25 Sirugo G, Williams SM, Tishkoff SA. The missing diversity in human genetic studies. Cell. 2019 May 2;177(4):1080.
26 Dick DM, Barr PB, Cho SB, Cooke ME, Kuo SI, Lewis TJ, et al. Post-GWAS in psychiatric genetics: a developmental perspective on the "other" next steps. Genes Brain Behav. 2018 Mar;17(3):e12447.

27 Peterson RE, Kuchenbaecker K, Walters RK, Chen CY, Popejoy AB, Periyasamy S, et al. Genome-wide association studies in ancestrally diverse populations: opportunities, methods, pitfalls, and recommendations. Cell. 2019 Oct 17;179(3):589-603.

28 Smith EN, Bloss CS, Badner JA, Barrett T, Belmonte PL, Berrettini W, et al. Genomewide association study of bipolar disorder in European American and African American individuals. Mol Psychiatry. 2009 Aug; 14(8): 755-63.

29 Frye MA, Doederlein A, Koenig B, McElroy SL, Nassan M, Seymour LR, et al. National survey and community advisory board development for a bipolar disorder biobank. Bipolar Disord. 2015 Sep;17(6):598-605.

30 Lemke AA, Wolf WA, Hebert-Beirne J, Smith ME. Public and biobank participant attitudes toward genetic research participation and data sharing. Public Health Genomics. 2010;13(6):368-77.

31 Halverson CM, Ross LF. Incidental findings of therapeutic misconception in biobankbased research. Genet Med. 2012 Jun;14(6): 611-5.

32 Gamble VN. A legacy of distrust: African Americans and medical research. Am J Prev Med. 1993 Nov-Dec;9(6 Suppl 1):35-8.

33 Washington HA. Medical apartheid: the dark history of medical experimentation on black Americans from colonial times to the present. New York, NY: Doubleday; 2006.

34 Sullivan LS. Trust, risk, and race in American medicine. Hastings Cent Rep. 2020 Jan; 50(1):18-26.

35 Wolinetz CD, Collins FS. Recognition of research participants' need for autonomy: remembering the legacy of Henrietta Lacks. JAMA. 2020 Sep;324(11):1027-8.

36 Braunstein JB, Sherber NS, Schulman SP, Ding EL, Powe NR. Race, medical researcher distrust, perceived harm, and willingness to participate in cardiovascular prevention trials. Medicine. 2008 Jan;87(1):1-9.

37 McDonald JA, Vadaparampil S, Bowen D, Magwood G, Obeid JS, Jefferson M, et al. Intentions to donate to a biobank in a national sample of African Americans. Public Health Genomics. 2014;17(3):173-82.

38 Porteri C, Pasqualetti P, Togni E, Parker M. Public's attitudes on participation in a biobank for research: an Italian survey. BMC Med Ethics. 2014 Nov 26;15:81.

39 U.S. Census Bureau. American Community Survey 1-Year Estimates, Table B01001 American Community Survey. data.census. gov; 2018.
Community Concerns for Bipolar Biobanking
Public Health Genomics 2021:24:89-98 
40 University of Mississippi Medical Center CfIa, Analytics. Patient Cohort Explorer. 2020.

41 R Core Team. R: a language and environment for statistical computing. Vienna, Austria: R Foundation for Statistical Computing; 2020.

42 Heinzen E, Sinnwell J, Atkinson E, Gunderson T, Dougherty G. arsenal: an arsenal of " $R$ " functions for large-scale statistical summaries. 2020

43 Nwulia EA, Hipolito MM, Aamir S, Lawson WB, Nurnberger JI Jr; BiGS Consortium. Ethnic disparities in the perception of ethical risks from psychiatric genetic studies. Am J Med Genet B Neuropsychiatr Genet. 2011 Jul;156(5):569-80.
44 McDonald JA, Barg FK, Weathers B, Guerra $\mathrm{CE}$, Troxel AB, Domchek S, et al. Understanding participation by African Americans in cancer genetics research. J Natl Med Assoc. 2012 Jul-Aug;104(7-8):324-30.

45 Passmore SR, Jamison AM, Hancock GR Abdelwadoud M, Mullins CD, Rogers TB, et al. "I'm a little more trusting": components of trustworthiness in the decision to participate in genomics research for African Americans. Public Health Genomics. 2019;22(56):215-26.
46 Misra S, Socherman R, Hauser P, Ganzini L. Appreciation of research information in patients with bipolar disorder. Bipolar Disord. 2008 Jul;10(5):635-46.

47 Stolzmann K, Meterko M, Miller CJ, Belanger L, Seibert MN, Bauer MS. Survey response rate and quality in a mental health clinic population: results from a randomized survey comparison. J Behav Health Serv Res. 2019 Jul;46(3):521-32.

48 Khubchandani J, Balls-Berry J, Price JH, Webb FJ. Community-engaged strategies to increase diversity of participants in health education research. Health Promot Pract. 2016 May; 17(3):323-7. 